\title{
Sanayi Tipi Domates Bitkisinde Su-Verim İlişkileri Üzerine Bir Araştırma
}

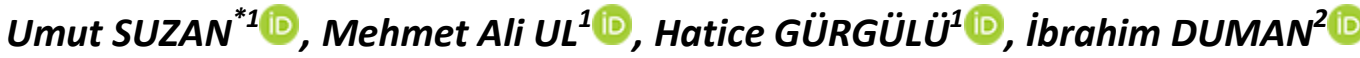

${ }^{1}$ Ege Üniversitesi, Ziraat Fakültesi, Tarımsal Yapılar ve Sulama Bölümü, Bornova, İmir

${ }^{2}$ Ege Üniversitesi, Ziraat Fakültesi, Bahçe Bitkileri Bölümü, Bornova, Izmir

Öz: Dünyada ve ülkemizde tatlı su kaynakları gün geçtikçe azalmaktadır. Sorunun çözümüne yönelik özellikle tarımsal üretimde suyu daha etkin kullanabilmek için çeşitli çalışmalar yapılmaktadır. Ülkemiz açısından önemli bir üretim alanına sahip olan sanayi domatesinde yapılan bu çalışma da bunlardan biridir. İzmir-Bornova koşullarında 2017 yılı yaz döneminde yürütülen çalışmada su-verim ilişkilerinin yanı sıra; bazı meyve kalite özellikleri, su kullanım randımanı ve sulama suyu kullanım randımanı değerlerinin belirlenmesi amaçlanmıştır. Sulama suyu miktarının belirlenmesinde A-sınıfı buharlaşma kabından yararlanılmış ve $I_{125}, I_{100}, I_{75}$ ve $I_{50}(\% 125, \% 100, \% 75$ ve \%50) sulama konuları uygulanmıştır. Verim miktarı sırasıyla $\% 125, \% 100, \% 75$ ve $\% 50$ sulama konuları için $1939.94 \mathrm{~kg} / \mathrm{da}, 1650.16 \mathrm{~kg} / \mathrm{da}, 1528.80 \mathrm{~kg} / \mathrm{da}$ ve $1409.10 \mathrm{~kg} / \mathrm{da}$ olarak saptanmıştır. Buna karşlık kalite değerlerinde en yüksek değerler \%50 sulama konusunda tespit edilmiştir. Bu konuda, titre edilebilir asitlik, suda çözünebilir kuru madde miktarı, meyve kuru ağırlı̆̆ı ve meyve sertliği değerleri sırasıyla 3.52 mval/100, \%6.20, $8.07 \mathrm{gr}$ ve $4.15 \mathrm{~N}$ olarak elde edilmiştir. Elde edilen sonuçlara göre, verim $\mathrm{x}$ kalite (briks) $\mathrm{x}$ randıman değeri ile çiftçiye ekonomik olarak daha çok gelir getireceği görüşünden hareketle, ele alınan sulama uygulamalarından $I_{75}$ ve $I_{50}$ konusunun çiftçiler için daha avantajlı olacağı sonucuna varıımıştır.

\section{Anahtar kelimeler: A-sınıfı buharlaşma kabı, sulama, meyve kalitesi}

\section{A Research On The Water-Yield Relationship In Proccessing Tomato Plants}

Abstract: The freshwater resources in the world including Turkey are decreasing day by day. In order to solve this problem, especially in agricultural production, various studies are being carried out to use the water more effectively. This study is conducted on processing tomato which has a significant production area in our country. It was carried out during the summer season in 2017 under the region conditions of izmir-Bornova. The aim of the study is to determinate the water-yield relations, some fruit quality characteristics, water use efficiency and irrigation water use efficiency. Pan evaporation method was used to determine the amount of irrigation water. Irrigation treatments were applied as $I_{125}, I_{100}, I_{75}$ and $I_{50}(125 \%, 100 \%, 75 \%$ and $50 \%$, respectively). Yields were determined as $1939.94 \mathrm{~kg} / \mathrm{da}, 1650.16$ $\mathrm{kg} / \mathrm{da}, 1528.80 \mathrm{~kg} / \mathrm{da}$ and $1409.10 \mathrm{~kg} / \mathrm{da}$ for $125 \%, 100 \%, 75 \%$ and $50 \%$ irrigation treatments, respectively. On the other hand, the highest values in quality were determined in $50 \%$ irrigation treatment. These quality values are titratable acidity, water soluble dry matter content, fruit dry weight and fruit hardness values as $3.52 \mathrm{mval} / 100,6.20 \%, 8.07 \mathrm{~g}, 4.15 \mathrm{~N}$, respectively. According to these results, it is thought that $I_{75}$ and $I_{50}$ irrigation of treatments have more advantageous, because this treatment with the high yield $x$ quality (briks) $x$ efficiency value will have more income in tomato production for the farmers.

Keywords: Class-A pan, irrigation, fruit quality

\section{GiRiş}

Türkiye'de yıllık kişi başına düşen kullanılabilir su miktarı $1,450 \mathrm{~m}^{3}$ tür ve bu değerin nüfus artışıyla birlikte daha da düşeceği öngörülmektedir. Ayrıca 1,450 $\mathrm{m}^{3}$ değeri baz alındığında, Türkiye su azlığı yaşayan ülke konumundadır (DSi, 2017). Bu durum su kaynaklarımızın verimli ve etkin bir şekilde kullanım zorunluluğunu ortaya koymaktadır.

Açık alanda yapılan üretim koşullarında bitkinin iklim isteklerinin tam olarak sağlanabilmesi için yaz döneminde yetiştirilmesi gerekir. Ülkemizde yaz aylarının çoğunlukla kurak geçmesi ve su kaynaklarının istenilen düzeyde olmaması, sulamanın bilinçli olarak gerçekleştirilmesini zorunlu kılmaktadır (Balçın, 1994). Sanayi domatesinde karık ve damla sulama yöntemleri ile 4 farklı su düzeyinde su-verim ilişkilerinin incelendiği araştırmada; sulamalar deneme alanına kurulmuş olan buharlaşma kabında meydana gelen birikimli buharlaşma miktarı ölçülerek gerçekleştirilmiştir. Karık sulama için $60 \mathrm{~mm}$, damla sulama için $30 \mathrm{~mm}$ olduğunda dört farklı pan katsayısı (kp) (0.35,
$0.70,1.05,1.4)$ ile çarpımından elde edilen sulama suyu miktarlarına göre sulamalar yapılmıştır. Konulara bağı olarak 181.63-726.53 mm arasında değişen miktarlarda sulama suyu verilmiştir. Ortalama en yüksek verim damla sulama ile sulanmış olan ve en yüksek su miktarı uygulanan 1.4 konusunda $3538.4 \mathrm{~kg} / \mathrm{da}$ olarak belirlenmiştir. Ortalama su kullanım randımanı değerleri damla sulama için 5.73, karık sulama için $6.125 \mathrm{~kg} / \mathrm{da} / \mathrm{mm}$ olarak tespit edilmiştir.

*Sorumlu Yazar: umutsuzan@gmail.com Bu çalışma yüksek lisans tez ürünüdür ve Ege Üniversitesi Bilimsel Araştırma Projeleri Koordinasyon Birimi tarafından desteklenmiştir (Proje No: 2017-ZRF-021). Çalışmanın özeti 6. Uluslararası Katılımlı Toprak ve Su Kaynakları Kongresinde (12-14 Kasım 2019) bildiri kitabına basılmıştır.

Geliş Tarihi: 12 Ekim 2020

Kabul Tarihi: 24 Mayıs 2021 
Ortalama verim tepki faktörü (ky) damla için 0.386, karık için 0.119 olarak elde edilmiştir. Mevsimlik ortalama bitki su tüketim değerleri ise $387.37-851.78 \mathrm{~mm}$ arasında değişmiştir (Gürbüz, 2001). Gerek dünyada gerekse de ülkemizde tatlı su kaynaklarından yaşanan sorunlar nedeniyle tarımsal alanda kullanılan sudan daha etkin yararlanılabilmesi ve verilen su miktarlarına bağlı olarak değişen kalite parametrelerinin belirlenmesi amacıyla çeşitli çalışmalar gerçekleştirilmektedir. Bu çalışmalarda kullanılan yöntemlerden biri de A sınıfı buharlaşma kapları ile bitki su tüketimini ve buna bağlı olarak sulama suyu miktarlarının tahmin edilmesidir. Bu çalışma ile dünyada ve Türkiye'de büyük bir üretim potansiyeline sahip olan domates bitkisinin A sınıfı buharlaşma kabı kullanılarak uygulanan farklı sulama suyu düzeylerinde verim ve kalite parametrelerinde meydana gelen değişimler belirlenmeye çalışılmıştır.

\section{MATERYAL VE YÖNTEM}

Araştırma, 2017 yılı ilkbahar-yaz döneminde Ege Üniversitesi Ziraat Fakültesi Bahçe Bitkileri Bölümü'ne ait arazide yürütülmüştür. Deneme alanının eni $14 \mathrm{~m}$, boyu $24.8 \mathrm{~m}$, alanı ise yaklaşı $350 \mathrm{~m}^{2}$ olacak şekilde düzenlenmiştir. Deneme alanı $38^{\circ} 27^{\prime}$ kuzey enlemi, $27^{\circ} 13^{\prime}$ doğu boylamında ve denizden $28 \mathrm{~m}$ yükseklikte bulunmaktadır. Denemenin yürütüldüğü arazideki toprakların sulama yönünden önemli fiziksel özelliklerini belirlenmesi için 2017 yılında $90 \mathrm{~cm}$ 'ye kadar toprak profili açılarak farklı katmanlardan $(0-30,30-60,60-90 \mathrm{~cm}) 3$ tekerrürlü bozulmuş ve bozulmamış toprak örnekleri alınmıştır. Yapılan analizler sonucunda toprak özellikleri Çizelge 1'de verilmiştir. Deneme alanında 2017 yılına ilişkin sıcaklık ortalamaları, uzun yıllar (1938-2017) sıcaklık ortalamalarının üzerinde seyretmiştir. 2017 yılında, bitki gelişim dönemi içerisinde oransal nem genelde mevsim normallerinin altındadır. Deneme yılına ilişkin rüzgar hızları incelendiğinde, mevsim normalleriyle paralellik göstermiştir. Yağış değerlerinde ise uzun yıllar ortalamalarının altında yağış olduğu gözlemlenmiştir.

Araştırma, tesadüf blokları deneme deseninde üç tekrarlı olarak yürütülmüş ve deneme konuları rastgele dağıtılmıştır. Her bir blokta 4 parsel yer almaktadır. Bir deneme parseli $5.60 \times 2.5 \mathrm{~m}$ boyutlarındadır.

Çizelge 1. Deneme alanı toprağının bazı fiziksel özellikleri

\begin{tabular}{cccccccc}
\hline $\begin{array}{c}\text { Derinlik } \\
(\mathbf{c m})\end{array}$ & Kil (\%) & Mil (\%) & Kum (\%) & Bünye & $\begin{array}{c}\text { Hacim Ağırlığı } \\
\left(\mathbf{g r} / \mathbf{c m}^{\mathbf{3}}\right)\end{array}$ & $\begin{array}{c}\text { Tarla Kap. } \\
\mathbf{( \% )} \text { Pw }\end{array}$ & $\begin{array}{c}\text { Solma Nok. } \\
(\%)\end{array}$ \\
\hline $0-30$ & 29.40 & 19.99 & 50.61 & $\mathrm{SCL}$ & 1.63 & 22.88 & 15.3 \\
$30-60$ & 26.79 & 15.69 & 57.52 & $\mathrm{SCL}$ & 1.74 & 21.1 & 13.94 \\
$60-90$ & 25.79 & 14.69 & 59.52 & $\mathrm{SCL}$ & 1.47 & 21.13 & 13.67 \\
\hline
\end{tabular}

Bir parselin alanı $14 \mathrm{~m}^{2}$ dir. Parsel sayısı 12'dir. Her bir parselde 4 adet bitki sırası ve her bir sırada 10 bitki yer almaktadır. Sıra üzeri $0.25 \mathrm{~m}$ sıra arası $1.40 \mathrm{~m}$ olacak şekilde fide dikimi yapılmıştır. Sulanan alan ise $168 \mathrm{~m}^{2 \prime}$ dir.

Deneme alanının yakınındaki havuzdan alınan su toprak altına döşenmiş olan borularla deneme alanına getirilmiştir. Sistemdeki vana üzerinden $32 \mathrm{~mm}$ çapında polietilen borularla alınan su parsellere ulaştırılarak, priz kolye aracılığıyla $16 \mathrm{~mm}$ çaplı kendinden damlatıcılı lateral boru hatlarına verilmiştir. Lateral boru hatları üzerinde bulunan damlatıcılar $0.25 \mathrm{~m}$ aralıklı ve 4 L/sa kapasiteli olarak seçilmiştir.

Sulama suyunun kalitesi $\mathrm{pH}(7.17 \pm 0.18)$, EC $(0.84 \pm 0.09 \mathrm{dS}$ $\left.\mathrm{m}^{-1}\right), \mathrm{Cl}\left(1.62 \pm 0.16 \mathrm{meq} \mathrm{L}^{-1}\right)$, sodyum adsorbsiyon oranı $(0.82 \pm 0.23)$ ve kalıcı sodyum karbonat $(-1.55 \pm 1.15$ meq $\mathrm{L}^{-1}$ ) cinsinden tanımlanmaktadır. Değerler, toprak sağlığını olumsuz etkilemeden bitkiler için sulama suyunun güvenli kullanımı için izin verilen sınırların altındadır (Ayers ve Westcot, 1994).

Denemede açık su yüzeyinden meydana gelen birikimli buharlaşma miktarının $0.50,0.75,1.00$ ve $1.25\left(k_{c p}\right)$ katsayıları ile çarpımlarından elde edilen 4 su düzeyi araştırılmıştır. Buna göre deneme konuları;

$I_{50}$ : $I_{100}$ konusuna uygulanan suyun $\% 50$ 'si kadar sulama suyu uygulanan konu,

$I_{75}: I_{100}$ konusuna uygulanan suyun $\% 75$ 'i kadar sulama suyu uygulanan konu,

$\mathrm{I}_{\mathbf{1 0 0}}$ : bitki su ihtiyacının, A sınıfı buharlaşma kabındaki buharlaşmaya göre tam olarak karşılandığı konu,

$I_{125}$ : $I_{100}$ konusuna uygulanan suyun $\% 125^{\prime} i$ kadar sulama suyu uygulanan konu olacak şekilde düzenlemiştir.

Denemenin başında topraktaki nem tarla kapasitesine gelecek kadar sulama suyu başlangıç sulaması olarak uygulanmış ve sonrasında fide kök sistemi gelişinceye kadar (5 hafta) tüm konulara eşit miktarda sulama suyu uygulanmıştır. Bitkilerin kök sistemi geliştikten sonra sulama konularına geçilmiştir. Sulama konularına verilecek su, deneme alanına kurulan A sınıfı buharlaşma kabından ölçülen yığışımlı (birikimli) açık su yüzeyi buharlaşma değerlerinin farklı oranları (\%125, \%100, \%75 ve \%50) şeklinde hesaplanarak uygulanmıştır. 
Sulama suyu miktarının hesabı ise aşağıdaki gibidir (Kanber, 1984; Ertek ve ark., 2006; Özbek, 2012).

\section{$I=A \times E_{p a n} \times K_{c p}$}

I: Parsele verilen sulama suyu miktarı (litre), A: Parsel alanı $\left(\mathrm{m}^{2}\right)$, $E_{\text {pan: }}$ Sulama aralığında A sınıfı buharlaşma kabında oluşan yığışımlı (birikimli) buharlaşma miktarı $(\mathrm{mm}), \mathbf{K}_{\mathrm{cp}}$ : Bitki-Kap kat sayısı (pan kat sayısı).

Söz konusu eşitliğe göre hesaplanan sulama suyu miktarları sistemde bulunan su sayacı ile denetlenerek uygulanmıştır. Burada buharlaşma ölçülürken dijital kumpastan yararlanılmış ve ölçümler üç günde bir yapılmıştır.

Bitki su tüketimi (evapotranspirasyon), bitkinin yapraklarından ve topraktan gerçekleşen buharlaşma miktarının toplamıdır. Evapotranspirasyon direkt olarak toprağa giren ve çıkan suyun takip edilmesiyle tespit edilebilmektedir. Hesaplamalarda su bütçesi eşitliği kullanılmıştır. Bu eşitlik kütlenin korunumu prensibine dayanır. Belli bir zaman içerisinde toprak içerisine giren su ile çıkan su miktarı arasındaki fark, bu toprağın hacmindeki su miktarında meydana gelen değişime eşittir. Evapotranspirasyon (ET) aşağıda verilen su bütçesi eşitliği kullanılarak hesaplanmıştır (Heerman, 1985).

\section{$E T=R+I-D \pm \Delta W$}

ET: Bitki su tüketimi (mm), R: Etkili yağış miktarı (mm), I: Sulama suyu miktarı $(\mathrm{mm})$, D: Drenaj $(\mathrm{mm}), \Delta \mathbf{W}$ : Toprak su depolanmasındaki değişim $(\mathrm{mm})$.

Su kullanım randımanları (WUE) sulama programlarının değerlendirilmesinde ve sulama yöntemlerinin karşılaştırılmasında kullanılan bir ölçüttür (Tanner ve Sinclair, 1983). Su kullanım randımanlarının belirlenmesinde, Howell ve ark. (1990) tarafından ortaya konulan eşitlik kullanılmıştır.

$$
W U E=\frac{E y}{E T}
$$

WUE: Su kullanım randımanı $(\mathrm{kg} / \mathrm{da} / \mathrm{mm})$, Ey: Ekonomik verim (kg/da), ET: Bitki su tüketimi (mm).

Bununla birlikte sulama suyu kullanım etkinliğinin (IWUE) belirlenmesinde ise aşağıda verilen eşitlik kullanılmıştır (Kanber ve ark., 1992).

$$
I W U E=\frac{E y}{I}
$$

IWUE: Sulama suyu kullanım etkinliği $(\mathrm{kg} / \mathrm{da} / \mathrm{mm})$, Ey: Ekonomik verim ( $\mathrm{kg} / \mathrm{da})$, I: Sulama suyu miktarı $(\mathrm{mm})$.

Çalışmada elde edilen tüm veriler IBM SPSS Statistical Package for Social Sciences Statistic 22 paket programında Duncan testi ile değerlendirilmiştir. Verilerin sayısal olarak dağılımlarının belirlenmesinde frekans analizi kullanılır. Analizler sonucunda ulaşılan verilere ilişkin standart sapma, mod, medyan, ortalama gibi değerlerin hesaplanmasında tanımlayıcı istatistikler kullanılır. Tanımlayıcı istatistikler ile
SUZAN U, UL MA, GÜRGÜLÜ H, DUMAN i frekans analizi temel analizler olup kolaylıkla yapılabilmektedir (Suzan, 2018).

\section{BULGULAR VE TARTIŞMA}

Bitki köklerinin gelişip toprağa iyi bir şekilde tutunabilmesi için 03.07.2017 tarihine kadar tüm konulara eşit miktarda su uygulaması (2334.2 litre) yapılmıştır. Bu tarihten itibaren konularda programlı sulama uygulamasına geçilmiş, konulara göre gerçekleştirilen sulamalar Çizelge 2'de verilmiştir.

Çizelge 2. Sulama kısıtı sonrası konulara uygulanan haftalık toplam

\begin{tabular}{|c|c|c|c|c|c|}
\hline \multirow{2}{*}{ Tarih } & \multirow{2}{*}{ Hafta } & \multicolumn{4}{|c|}{ Konular } \\
\hline & & $\mathrm{I}_{125}$ & $I_{100}$ & $\mathrm{I}_{75}$ & $I_{50}$ \\
\hline \multicolumn{6}{|l|}{ 06-12 Temmuz } \\
\hline 2017 & 1 & 1728.9 & 1383.1 & 1037.3 & 691.5 \\
\hline \multicolumn{6}{|l|}{ 13-19 Temmuz } \\
\hline 2017 & 2 & 3034.5 & 2427.6 & 1820.7 & 1213.8 \\
\hline \multicolumn{6}{|l|}{ 20-26 Temmuz } \\
\hline 2017 & 3 & 2446.0 & 1956.8 & 1467.6 & 978.4 \\
\hline \multicolumn{6}{|l|}{27 Temmuz -02 } \\
\hline \multicolumn{6}{|l|}{ 03-09 Ağustos } \\
\hline 2017 & 5 & 2712.2 & 2169.8 & 1627.3 & 1084.9 \\
\hline \multicolumn{6}{|l|}{ 10-16 Ağustos } \\
\hline $\begin{array}{c}2017 \\
\text { 17-20 Ağustos }\end{array}$ & 6 & 3080.7 & 2464.6 & 1848.4 & 1232.3 \\
\hline 2017 & 7 & 3019.3 & 2415.4 & 1811.6 & 1207.7 \\
\hline $\begin{array}{c}\text { Toplam Sulama } \\
\text { Suyu }\end{array}$ & & 20580.0 & 16329.1 & 12078.3 & 7827.4 \\
\hline
\end{tabular}
sulama suyu miktarları(litre)

Çizelge 2'den de görülebileceği gibi, mevsimlik toplam sulama suyu miktarları $I_{125}$ uygulaması için 20580.2 litre, $I_{100}$ uygulaması için 16329.1 litre, $I_{75}$ uygulaması için 12078.3 litre ve $\mathrm{I}_{50}$ uygulaması için 7827.4 litre olarak hesaplanmıştır. Konulara en çok sulama suyunun verildiği hafta dördüncü haftadır. Bu durum söz konusu dönemde artan sıcaklığa bağlı olarak buharlaşma miktarının artmasından kaynaklanmıştır. En çok sulama suyu uygulanan konu $I_{125}$ konusudur. Bunu sirasiyla $I_{100}, I_{75}$ ve $I_{50}$ konuları takip etmiştir. Ayrıca ilk haftalarda uygulanan sulama miktarı daha az iken, son haftalarda sıcaklık artışına bağlı olarak uygulanan sulama suyu miktarları da artmıştır. Toplam sulama suyu miktarı (litre/bitki), toplam sulama suyu miktarı $(\mathrm{mm})$ ve mevsimlik bitki su tüketim ( $\mathrm{mm}$ ) değerleri Çizelge 3'de verilmiştir. Söz konusu çizelgeye göre, bitki başına toplam sulama suyu miktarları $I_{125}, I_{100}, I_{75}$ ve $I_{50}$ konuları için sırasıyla; 191.0 litre/bitki, 155.5 litre/bitki, 120.1 litre/bitki ve 84.7 litre/bitki olarak gerçekleşmiştir. Deneme konularına ilişkin toplam sulama suyu miktarı ise $I_{125}, I_{100}, I_{75}$ ve $I_{50}$ konuları için sırasıyla $545.58 \mathrm{~mm}, 444.36$ $\mathrm{mm}, 343.15 \mathrm{~mm}$ ve $241.94 \mathrm{~mm}$ olarak belirlenmiştir. Mevsimlik bitki su tüketimi değerleri 585.25 ile 305.66 mm arasında değişiklik göstermiştir. En düşük mevsimlik bitki su tüketimi değeri $305.66 \mathrm{~mm}$ ile $\mathrm{I}_{50}$ uygulamasından, en yüksek mevsimlik bitki su tüketim değeri ise $585.25 \mathrm{~mm}$ ile $\mathrm{I}_{125}$ uygulamasından elde edilmiştir. 
Çizelge 3. Uygulanan toplam sulama suyu miktarları (litre/bitki); $(\mathrm{mm})$ ve mevsimlik bitki su tüketimi $(\mathrm{mm})$

\begin{tabular}{cccc}
\hline Konular & $\begin{array}{c}\text { Toplam Sulama } \\
\text { Suyu Miktarı } \\
\text { (litre/bitki) }\end{array}$ & $\begin{array}{c}\text { Toplam } \\
\text { Sulama Suyu } \\
\text { Miktarı }(\mathbf{m m})\end{array}$ & $\begin{array}{c}\text { Mevsimlik } \\
\text { Bitki Su } \\
\text { Tüketimi } \\
(\mathbf{m m})\end{array}$ \\
\hline $\mathrm{I}_{125}$ & 191.0 & 545.58 & 582.25 \\
$\mathrm{I}_{100}$ & 155.5 & 444.36 & 545.37 \\
$\mathrm{I}_{75}$ & 120.1 & 343.15 & 358.59 \\
$\mathrm{I}_{50}$ & 84.7 & 241.94 & 305.66 \\
\hline
\end{tabular}

Domates bitkisi ile yapılan su kısıtı çalışmalarında araştırmacılar farklı miktarlarda su uygulamıştır. Gürbüz (2001) Büyük Menderes Ovası'nda yaptığı çalışmada, 0.35, $0.70,1.05$ ve 1.40 pan katsayılarını kullanmıştır. Çalışmada uygulanan sulama suyu miktarı 181.63 ile $726.53 \mathrm{~mm}$ arasında değişiklik göstermiştir. Bahar (2008)'ın Samsun koşullarında gerçekleştirdiği diğer bir çalışmada ise 0.00 , $0.25,0.50,0.75$ ve 1.00 pan kat sayıları kullanılmış, uygulanan sulama suyu miktarları ise 79.30 ile $479.93 \mathrm{~mm}$ arasında değişmiştir. Bu çalışmadan elde edilen sonuçlar söz konusu araştırmaların sonuçları ile paralellik göstermiştir.

Mevsimlik bitki su tüketim değerleri ise Gürbüz (2001)'ün çalışmasında 355.37 ile $851.78 \mathrm{~mm}$ arasında değişiklik göstermiştir. Sulama suyu miktarlarına bağlı olarak bu çalışma söz konusu olan çalışma ile benzerlik göstermektedir. Bahar (2008)'ın çalışmasında mevsimlik bitki su tüketimi değerlerinin 205.32 ile $506.2 \mathrm{~mm}$ arasında olduğu belirtilmiştir. Çalışmada elde edilen sulama suyu miktarları, söz konusu verilerle benzerlik göstermektedir. Deneme konularına göre bitki başına elde edilen verim ile dekara elde edilen verim değerleri Çizelge 4'de verilmiştir. $\mathrm{I}_{125}$ konusunda bitki başına en yüksek verim $0.78 \mathrm{~kg} / \mathrm{bitki}$ elde edilmiştir. En yüksek dekar verim değeri $\mathrm{I}_{125}$ konusunda $1939.94 \mathrm{~kg} / \mathrm{da}$ olarak bulunmuş ve istatiksel olarak birinci grupta yer almıştır. $I_{100}$ konusunun bitki başına verim değeri $0.65 \mathrm{~kg} /$ bitki olarak elde edilirken, dekar verimi ise 1650.16 $\mathrm{kg} /$ da olarak gerçekleşmiş ve ikinci grubu oluşturmuştur. $I_{75}$ konusunda ise bitki başına verim $0.55 \mathrm{~kg} / \mathrm{bitki}$ olarak tespit edilirken, dekar verim değeri $1528.80 \mathrm{~kg} / \mathrm{da}$ olarak saptanmış ve üçüncü grupta yer almıştır. Su kısıtının en etkin olduğu $I_{50}$ konusunda 0.49 kg/bitki ile 1409.10 kg/da en düşük verim değerleri elde edilmiş ve son grupta olduğu belirlenmiştir.

Çizelge 4. Konulara göre verim değerleri

\begin{tabular}{ccl}
\hline Konular & Verim $(\mathrm{kg} / \mathrm{bitki})$ & Verim $(\mathrm{kg} / \mathrm{da})$ \\
\hline $\mathrm{I}_{125}$ & $0.78 \mathrm{a}^{* *}$ & $1939.94 \mathrm{a}^{* *}$ \\
$\mathrm{I}_{100}$ & $0.65 \mathrm{~b}$ & $1650.16 \mathrm{~b}$ \\
$\mathrm{I}_{75}$ & $0.55 \mathrm{c}$ & $1528.80 \mathrm{c}$ \\
$\mathrm{I}_{50}$ & $0.49 \mathrm{~d}$ & $1409.10 \mathrm{~d}$ \\
\hline Ortalama & $0.62^{* *}$ & $1632^{* *}$ \\
\hline$* *: P<0.01^{\prime}$
\end{tabular}

$* *: P<0.01$ 'e göre önemli
Verim miktarları Tüzün (2006), Taşan (2006), Gürbüz (2001) ve He ve Lı (2014) çalışmalarının değerleri ile benzerlik göstermiştir. Sonuç olarak, sulama suyu miktarı düştükçe verim miktarlarında da bir düşüş gözlemlenmiştir.

Söz konusu çalışmanın verim miktarlarının genel olarak düşük çıkma sebebi ise domates fidelerinin dikim zamanıyla ilgilidir. Bölge koşullarında dikim zamanı nisan ayı içerisindedir. Aslında ilk domates fideleri bölge koşullarına uygun olarak nisan ayında dikilmiştir ama bakteriyel kanser (Clavibacter michiganensis) sebebiyle fideler dikimden bir ay sonra sökülmek zorunda kalınmıştır. Fideler mayıs ayında tekrar dikildiğinde ise yaz sıcaklıkları bastırmış, bitkiler istenilen şekilde gelişememiş ve söz konusu olan durum da verimi düşürmüştür.

Titre edilebilir asit miktarları (mval/100 ml), suda çözünebilir kuru madde miktarı (\%), meyve kuru ağırlık (gr) ve meyve sertliği değeri (N) Çizelge 5 'te verilmiştir. Çizelge 5'e göre titre edilebilir asit miktarları su kısıtı uygulanan konular arasında $\mathrm{P}<0.05$ hata ile önemli bulunmuştur. En yüksek titre edilebilir asit değerinin 3.52 mval / $100 \mathrm{ml}$ olarak $I_{50}$ uygulamasında, en düşük değerin ise 2.94 mval / $100 \mathrm{ml}$ ile $\mathrm{I}_{125}$ sulama uygulamasında olduğu belirlenmiştir. Meyvelerin hasat ve olgunluk zamanının belirlenmesinde önemli bir kalite parametresi olan suda çözünebilir kuru madde miktarında $\mathrm{P}<0.01$ hata ile önemli bir farklılık olduğu görülmektedir. Bu sonuca göre $I_{50}$ konusu 6.20 değeri ile en yüksek sonucu vermiş ve birinci grupta yer almıştır. $I_{75}$ sulama uygulaması 5.43 değeri ile ikinci grupta, $\mathrm{I}_{100}$ sulama uygulaması ise 5.17 değeri ile üçüncü grupta çıkmıştır. En düşük sonucu veren $I_{125}$ uygulaması ise 4.97 değeri ile dördüncü gruptadır. Bu sonuçlara göre, uygulanan sulama suyu miktarı artışının suda çözünebilir kuru madde miktarı değerlerinde düşüşe neden olacağı ifade edilebilir. Meyve kuru ağırlık değerlerinde \%99 güvenle önemli bir farklılık olduğu saptanmıştır. Buna göre en fazla su kısıtı uygulanan $\mathrm{I}_{50}$ konusunda $8.07 \mathrm{gr}$ ile diğer sulama konuları arasında en yüksek değeri elde edilmiş ve birinci grupta yer almıştır. $I_{50}$ konusuna göre daha az kısıt uygulanan $I_{75}$ konusunun 7.50 gr ile ikinci grupta yer aldığı tespit edilmiş ve $\mathrm{I}_{100}$ konusu da $7.30 \mathrm{gr}$ ile istatistiksel olarak üçüncü grupta yer almıştır. Son olarak en düşük değeri veren $\mathrm{I}_{125}$ konusunun ise $6.71 \mathrm{gr}$ ile dördüncü grupta olduğu belirlenmiştir. Bu sonuçlara göre; yine suda çözünebilir kuru madde miktarındaki gibi uygulanan sulama suyu miktarı artışının meyvedeki kuru ağırlık (gr) değerlerinde düşüşe neden olacağı şeklinde yorumlanabilir. Meyvelerin sertlik değerlerinde ise $I_{50}$ sulama uygulaması $4.15 \mathrm{~N}$ değeri ile en yüksek meyve sertliğini vermiş olup birinci grupta yer almıştır. $I_{75}, I_{100}, I_{125}$ konuları ise ikinci grupta yer almıştır. Bu konuların değerleri sırasıyla $3.55,3.42$ ve $3.27 \mathrm{~N}$ olarak saptanmıştır. Tüzün (2006)'ün yaptığı çalışmada sulama suyu miktarı azalırken titre edilebilir asitlik değerinin arttığı bilgileri bu çalışmanın 
verileri ile örtüşmektedir. Sanayi domatesinde sulama miktarı artıkça yüksek verim ve düşük SÇKM elde edilirken, sulama miktarı düştükçe düşük verim ve yüksek SÇKM değerleri elde edilir (Baselga ve ark., 1993; Hanson ve May; 2004; Bahar, 2008).

Çizelge 5. Konulara göre titre edilebilir asit (TA), suda çözünebilir kuru madde miktarı (SÇKM), meyve kuru ağırlık (MKA) ve meyvelerin sertlik değerleri (MS)

\begin{tabular}{ccccc}
\hline Konular & $\begin{array}{c}\text { TA } \\
\text { (mval/100 ml) }\end{array}$ & $\begin{array}{c}\text { SÇKM } \\
\text { (\%) }\end{array}$ & $\begin{array}{c}\text { MKA } \\
\text { (gr) }\end{array}$ & $\begin{array}{c}\text { MS } \\
\text { (N) }\end{array}$ \\
\hline $\mathrm{I}_{125}$ & $2.94 \mathrm{~b}$ & $4.97 \mathrm{c}$ & $6.71 \mathrm{c}$ & $3.27 \mathrm{~b}$ \\
$\mathrm{I}_{100}$ & $2.98 \mathrm{~b}$ & $5.17 \mathrm{bc}$ & $7.30 \mathrm{~b}$ & $3.42 \mathrm{~b}$ \\
$\mathrm{I}_{75}$ & $3.21 \mathrm{ab}$ & $5.43 \mathrm{~b}$ & $7.50 \mathrm{ab}$ & $3.55 \mathrm{~b}$ \\
$\mathrm{I}_{50}$ & $3.52 \mathrm{a}^{*}$ & 6.20 & $8.07 \mathrm{a}^{* *}$ & $4.15 \mathrm{a}^{* *}$ \\
& & $\mathrm{a}^{* *}$ & & \\
\hline Ortalama & $3.16^{*}$ & $5.44^{* *}$ & $7.39^{* *}$ & $3.60^{* *}$ \\
\hline
\end{tabular}

${ }^{*}, P<0.05 ;{ }^{* *}, P<0.01^{\prime}$ e göre önemli

Tüzün (2006)'ün yaptığı çalışmada sulama suyu miktarı azalırken titre edilebilir asitlik değerinin arttığı bilgileri bu çalışmanın verileri ile örtüşmektedir. Sanayi domatesinde sulama miktarı artıkça yüksek verim ve düşük SÇKM elde edilirken, sulama miktarı düştükçe düşük verim ve yüksek SÇKM değerleri elde edilir (Baselga ve ark., 1993; Hanson ve May; 2004; Bahar, 2008). Sulama uygulamalarına bağlı olarak kuru meyve ağılıklarının Lovelli ve ark. (2007) ile aynı doğrultuda istatistiksel olarak anlamlı olduğu sonucuna ulaşılmıştır. Meyve sertlik analizlerinde alınan sonuçlar ise Bahar (2008) sonuçları ile paralellik göstermiştir.

Araştırmada elde edilen su kullanım randımanı ve sulama suyu kullanım randımanı Çizelge $6^{\prime}$ da verilmiştir. Söz konusu çizelgede en yüksek su kullanım randımanı değeri $I_{50}$ uygulamasından elde edilmiştir. Aynı zamanda $I_{50}$ ve $I_{75}$ konusu birbirine çok yakın sonuç vermiştir. En yüksek sulama suyu kullanım randımanı ise $I_{50}$ konusundan elde edilmiştir.

Çizelge 6. Su kullanım randımanı ve sulama suyu kullanım randımanı

\begin{tabular}{ccc}
\hline Konular & $\begin{array}{c}\text { Su Kullanım } \\
\text { Randımanı (WUE) } \\
(\mathbf{k g} / \mathrm{da} / \mathrm{mm})\end{array}$ & $\begin{array}{c}\text { Sulama Suyu } \\
\text { Kullanım } \\
\text { Randımanı } \\
\text { (IWUE) } \mathbf{( k g / d a / m m )}\end{array}$ \\
\hline $\mathrm{I}_{125}$ & 9.94 & 10.67 \\
$\mathrm{I}_{100}$ & 8.41 & 10.32 \\
$\mathrm{I}_{75}$ & 13.48 & 14.08 \\
$\mathrm{I}_{50}$ & 13.82 & 17.46 \\
\hline
\end{tabular}

Tüzün (2006)'ün yaptığı çalışmada WUE değerleri 14.61 ile $10.48 \mathrm{~kg} / \mathrm{da} / \mathrm{mm}$ arasında değişirken, IWUE değerleri ise 16.03 ile $9.66 \mathrm{~kg} / \mathrm{da} / \mathrm{mm}$ arasında değişiklik göstermiştir. Elde edilen bu veriler deneme sonuçları ile benzerlik göstermektedir. Ayrıca söz konusu çalışmadaki sonuçlar Giuliani ve ark. (2016) ve Lovelli ve ark. (2017)'nin yürüttükleri çalışmaların sonuçları ile örtüşmektedir.

\section{SONUÇ}

Damla sulama yöntemiyle sulanan sanayi tipi domates bitkisinde su verim ilişkilerinin belirlenmesi amacıyla yürütülen araştırmada, bitki su ihtiyacının tam olarak karşılandığı $\left(I_{100}\right)$ durumda bitkiye uygulanan toplam sulama suyu miktarı $444.36 \mathrm{~mm}$, mevsimlik bitki su tüketimi ise $545.37 \mathrm{~mm}$ olarak belirlenmiştir. Bu koşullarda bitkinin verim değeri $1650.16 \mathrm{~kg} / \mathrm{da}$ olarak belirlenmiştir. $\mathrm{I}_{125}$ konusunda bitkiye uygulanan toplam sulama suyu miktarı $545.58 \mathrm{~mm}$, mevsimlik su tüketim değeri $582.25 \mathrm{~mm}$, verim değeri ise $1939.94 \mathrm{~kg} / \mathrm{da}$ olarak hesaplanmıştır. $\mathrm{I}_{75}$ konusunda bitkiye uygulanan toplam sulama suyu miktarı $343.15 \mathrm{~mm}$ olarak belirlenmiş, bitkinin su tüketimi 358.59 mm olmuştur. $I_{75}$ konusunun verim değeri de $1528.80 \mathrm{~kg} / \mathrm{da}$ olarak belirlenmiştir. Son olarak $\mathrm{I}_{50}$ konusunda toplam sulama suyu miktarı $241.94 \mathrm{~mm}$, bitki su tüketim değeri ise $305.66 \mathrm{~mm}$ olarak elde edilmiştir. En az su uygulanan $\mathrm{I}_{50}$ konusunun verim değeri $1409.10 \mathrm{~kg} / \mathrm{da}$ olarak belirlenmiştir. Bu sonuçlara göre uygulanan sulama suyu miktarı artıkça verimin artış gösterdiği tespit edilmiştir. Kalite özelliklerinin tespit edilmesinde kullanılan titre edilebilir asit, suda çözünebilir kuru madde miktarı, meyve kuru ağırlığı ve meyve sertliği toplam sulama suyu miktarının azalmasıyla istatistiki olarak artış göstermiştir. En yüksek değerler $\mathrm{I}_{50}$ konusunda sırasıyla 3.16 mval / $100 \mathrm{ml}$, $\% 5.44,7.39$ gr ve $3.60 \mathrm{~N}$ olarak elde edilmiştir.

Su kaynaklarındaki kısıt koşullarının arttığı tarımsal üretimin yapıldığı yerlerde, yetiştiriciliği yapılacak bitki ile uygulanacak sulama suyu miktarının tespit edilmesinde önemli bir kriter olan WUE ve IWUE değerleri $I_{50}$ sulama suyu uygulamasında en yüksek çıkmıştır. WUE 13.82 $\mathrm{kg} / \mathrm{da} / \mathrm{mm}$ iken IWUE değeri $17.46 \mathrm{~kg} / \mathrm{da} / \mathrm{mm}$ olmuştur. Bu sonuçlar göstermektedir ki bölge koşullarında bitki su ihtiyacının \%75'nin karşılanması halinde $\left(I_{75}\right)$ bitki kalite parametreleri ile birlikte WUE ve IWUE değerleri de artmaktadır. Verim ise $1528.80 \mathrm{~kg} /$ da olarak çıkmakta ve $\mathrm{I}_{100}$ ile $\mathrm{I}_{125}$ konularından sonra istatiksel olarak bu değerle üçüncü grupta yer almaktadır. Bu durum sonucunda $I_{75}$ konusu tavsiye edilebilir. Ayrıca $I_{50}$ konusunun da verim değerlerinin istatistiksel olarak en düşük miktarda çıkmasına rağmen kalite, WUE ve IWUE değerlerinde istatistiksel olarak en yüksek miktarda çıkması su kısıtı koşullarında bu su uygulamasının da kullanılabileceğini göstermektedir. Bu değerlendirmelere göre yıllar bazında değişmekle birlikte verim $x$ kalite (briks) x randıman değeri ile çiftçiye ekonomik olarak daha çok gelir sağlayabileceğinden hareketle sulama uygulamalarında $I_{75}$ ve $I_{50}$ konuları çiftçiler için bir avantaj oluşturabilecektir. Bu durumda Bornova koşullarında damla sulama yöntemi ile sulanan sanayi domatesi yetiştiriciliğinde kısıt koşullarında en uygun sulama suyu miktarı bitki su ihtiyacının \%75'inin $\left(I_{75}\right)$ ve \%50'sinin $\left(I_{50}\right)$ uygulandığı sulama suyu miktarı olarak belirlenmiştir. Sonuç olarak bu çalışmanın, temiz su 
kaynaklarının azaldığı ve sanayi domatesinde verimden çok kaliteye önem verildiği günümüz koşullarında üreticiye yol gösteren bir niteliğe sahip olduğu düşünülmektedir.

\section{TEŞEKKÜR}

Bu çalışma kapsamında Ege Üniversitesi Bilimsel Araştırma Projeleri Koordinatörlüğüne verdikleri maddi destek için teşekkür ederiz.

\section{KAYNAKLAR}

Ayers RS, Westcot DW (1994) Water Quality for Agriculture, FAO Irrigation and Drainage Paper 29 Rev. 1. Food and Agriculture Organization of the United Nations, Rome.

Bahar S (2008) Organik Tarım Koşullarında Damla Sulama Yöntemi ile Sulanan Domates Bitkisinin A Sınıfı Buharlaşma Kaplarından Yararlanarak Sulama Programının Oluşturulması. Yüksek Lisans Tezi, Çanakkale Onsekiz Mart Üniversitesi, Çanakkale.

Balçın M (1994) Tokat Kazova'da Hıyar Su Tüketiminin Tarla Şartlarında Tespiti. Yüksek Lisans Tezi, Ondokuz Mayıs Üniversitesi, Samsun.

Baselga YJJ, Prieto LMH, Rincón ARD (1993) Response of Processing Tomato to Three Different Levels of Water And Nitrogen Applications. Acta Horticulturae 335: 97-108.

DSi (2017) Toprak ve Su Kaynakları. http://dsi.gov.tr/toprak-ve-su-kaynaklari (Erişim Tarihi: 14/02/2018)

Ertek A, Şensoy S, Gedik I, Küçükyumuk C (2006) Irrigation Scheduling Based on Pan Evaporation Values for Cucumber Grown Under Field Conditions. Agricultural Water Management 81: 159-172.

Gürbüz T (2001) Sanayi Domatesinde Farklı Sulama Yöntemleri ve Su Düzeylerinin Su-Verim Iliş̧kilerini Üzerine Etkilerinin İncelenmesi. Yüksek Lisans Tezi, Adnan Menderes Üniversitesi, Aydın.

Giuliani MM, Gatta G, Nardella E, Tarantino E (2016) Water Saving Strategies Assessment on Processing Tomato Cultivated in Mediterranean Region. Italian Journal of Agronomy 11(738) : 69 - 75.

Hanson B, May D (2004) Effect of Subsurface Drip Irrigation on Processing Tomato Yield, Water Table Depth, Soil
Salinity and Profitability. Agricultural Water Management 68: 1-17.

He H, L J (2013) Irrigation Schedule of Greenhouse Tomato Using Pan Evaporation and Tensiometer and Effects on Yield and Soil Nitrate. Advanced Materials Research 1162(8985) : 864 - 867.

Heerman DF (1985) ET in Irrigation Management, in Proceedings of the National Conference on Advances in Evapotranspiration. ASAE Publication. America.

Howell TA, Cuenca RB, Solomon KH (1990) Crop Yield Response. Management of Farm Irrigation Systems. American Society of Association Executives. America.

Kanber R (1984) Çukurova Koşullarında Açık Su Yüzeyi Buharlaşmasından Yararlanarak Birinci ve İkinci Ürün Yer Fıstığının Sulanması. Cilt 64. Bölge Toprak Su Araştırma Enstitüsü Yayınları. Adana.

Kanber R, Yazar A, Köksal H, Oğuzer V (1992) Evapotranspiration of Grapefruit in The Eastern Mediterranean Region of Turkey. Science Horticultural 52: 53-62.

Lovelli S, Potenza G, Castronuovo D, Perniola M, Candido V (2017) Yield, Quality and Water Use Efficiency of Processing Tomatoes Producuced Under Different Irrigation Regimes in Mediterranean Environment. Italian Journal of Agronomy 12(795) : 17 - 23.

Özbek Ö (2012) Farklı Kısıntılı Sulama Uygulamalarının Sera Koşullarında Yetiştirilen Patlıcanda Bitki Su Tüketimi, Verim ve Kalite Parametrelerine Etkileri. Yüksek Lisans Tezi, Akdeniz Üniversitesi, Antalya.

Suzan U (2018) Sanayi Tipi Domates Bitkisinde Su-Verim İlişkilerinin Belirlenmesi Üzerine Araştırması. Yüksek Lisans Tezi, Ege Üniversitesi, İzmir.

Tanner OB, Sinclair TR (1983) Efficient Water Use in Crop Production; Research Limitation to Efficient Water Use in Crop Production. SSSA, Madison. America.

Taşan M (2006) Samsun Koşullarında Domates Bitki Su Tüketiminin Belirlenmesi. Yüksek Lisans Tezi, Ondokuz Mayıs Üniversitesi, Samsun.

Tüzün i (2006) Domatesin Su-Üretim Fonksiyonları. Yüksek Lisans Tezi, Trakya Üniversitesi, Edirne. 